\title{
JOSÉ LAMBERT
}

José Lambert, um dos grandes nomes da romanística e da Literatura Comparada, foi um dos fundadores, junto com o norte-americano James S. Holmes e o israelense Gideon Toury, da disciplina Estudos da Tradução. Professor e pesquisador da Katholieke Universiteit Leuven, na Bélgica, José Lambert está na UFSC até agosto de 2009, como professor visitante estrangeiro, com bolsa do CNPq, a convite da Pós-Graduação em Estudos da Tradução (PGET), quando participará de cursos, oficinas, eventos, bancas e co-orientações. O professor José Lambert, que presidiu várias associações internacionais, é autor de uma vasta obra teórica e crítica, consubstanciada em livros e artigos publicados em vários países e línguas. É co-fundador, com Gideon Toury, e presidente de um dos mais importantes centros de pesquisa em Estudos da Tradução: o CETRA, na Universidade de Leuven, que está completando 20 anos em agosto deste ano. O CETRA foi criado para promover a pesquisa e o estudo da tradução bem como para estimular a pesquisa de alto nível. José Lambert é também um dos fundadores e editores de Target, o principal periódico da área de Estudos da Tradução.

Andréia Guerini e Walter Carlos Costa UFSC

Cadernos de Tradução (CT): Embora você seja formado em filologia românica e tenha trabalhado com literatura comparada, a tradução esteve sempre presente nos seus estudos. Como você vê a relação da Literatura Comparada com os Estudos da Tradução?

José Lambert (JL): É certo que a maior parte dos colegas, romanistas, filólogos, especialistas de letras vêem um conflito en- 
tre estas diferentes especialidades, mas eu mesmo jamais partilhei de tal ponto de vista. No momento em que pude escolher o tema de um trabalho de conclusão de curso na graduação, selecionei vários assuntos sobre a tradução literária, entre os quais "Kafka em tradução francesa" e lembro-me das várias questões que pretendia resolver. Várias delas ainda estão presentes em minhas pesquisas do século XXI. Mas volto ao cerne do problema. Se os pesquisadores em ciências humanas têm sobre o assunto opiniões diferentes, diria que é problema deles, e não meu. Perguntei-me frequentemente - inclusive em minhas publicações - como os especialistas da língua e das literaturas podem justificar a exclusão dos fenômenos de tradução de seu campo de estudos, sendo que se trata visivelmente de fatos de língua ou de língua literária ou de discurso. Creio poder - e dever - responder em seu lugar (as respostas através da história variam, certamente, e não posso tratá-las todas em duas frases). O simples fato de que a questão da tradução seja frequentemente excluída das grandes (e brilhantes) obras sobre a linguagem e sobre as literaturas indica até que ponto os pesquisadores mais brilhantes se contentam com definições (implícitas ou explícitas) que lhes foram legadas pela história ao invés de explorar verdadeiramente os conceitos dos quais se servem.

Aqueles que intervêm na história após o estabelecimento do Estado e após o estabelecimento do culto da língua nacional acham geralmente que seu universo pode se deter nas fronteiras do que é nacional, e isso até os dias de hoje, em plena mundialização. Quanto aos estudiosos dos séculos anteriores, dignaram-se em falar das traduções, de vez em quando, ou, antes, dos grandes tradutores. Em todas estas situações, a tradução parece merecer ser excluída porque "menos merecedora", tudo isto em virtude de concepções no que tange às prioridades nas ciências da linguagem que parecem escapar a uma aproximação racional.

CT: Você poderia falar um pouco sobre a questão da tradução, a institucionalização e a dinâmica literária das sociedades? 
$J L$ : A pesquisa sobre as traduções também deveria enrubecer um pouco. Formou-se tardiamente e, por isso, as muitas constatações capitais se formularam somente aos poucos. A convicção de que a tradução preenche um papel, uma função no bojo das sociedades amplia de maneira ambiciosa o campo de estudos e redefine o objeto a ser estudado: nos anos 60 e depois a tradução foi geralmente percebida como um fato de linguagem (muitas vezes exclusivamente como um fenômeno relativo às línguas nacionais), consequentemente relevando da linguística. Atualmente, isso não é incorreto, mas é estreito demais, e a posição acadêmica das pesquisas sobre tradução não deixa de sofrer com isso. Foi desde que Toury (e outros, cada vez mais) estabeleceu que a questão é em primeiro lugar um caso de "normas" que as línguas não suprem mais. Pois as línguas também, é claro, são submetidas a normas, não são portanto mais autônomas que as traduções. A idéia das normas encontra de fato sua origem na sociologia, e lembra-nos que é bem ingênuo enclausurar os fenômenos culturais em disciplinas ditas autônomas. Na realidade as universidades gostam de falar de interdisciplinaridade, mas tornam-se culpadas da hiper-especialização a ponto de asfixiar a pesquisa. Ora, as implicações ao evidenciar as normas foram formuladas aos poucos. A ideia de institucionalização deve-se ao impacto crescente de certa sociologia entre os especialistas da tradução. Pensamos sobretudo na sociologia de Bourdieu. Por que ela? Primeiro, sem dúvida, os grupos em volta de Bourdieu - antes que o próprio sociológo reconheceram a questão das traduções (até das traduções literárias) como fato social de importância capital. Além disso, porque se trata de uma sociologia que explora sobretudo a circulação dos bens simbólicos dentro do Estado nacional (o artigo que Bourdieu consagrou à circulação dita internacional data de 1991, e não reflete verdadeiramente uma maturidade frente ao programa em questão). Mas o essencial de sua pergunta não está aí. Como passar da questão das traduções à dinâmica das sociedades? (Não limitarei de forma alguma uma tal dinâmica às traduções literárias, sendo que é capital aceitar a ideia segundo a qual a fundação dos Estados nacionais deve muito à importância de obras literárias em tradução, ou, na termino- 
logia de Bourdieu: à circulação internacional dos bens simbólicos (pensemos em Walter Scott, mas também nas ideias de Herder, ou em Ossian, um dos modelos da nova poesia dos românticos). A ideia segundo a qual as sociedades seriam devedoras da tradução em suas dinâmicas fundamentais, creio desenvolvê-la melhor em meu artigo sobre a tradução jurídica (a ser publicado em um volume sobre Law and Language, MacMillan). O desenvolvimento das Constituições nacionais, de todos os tempos e países, é um belo exemplo de circulação internacional: a estrutura das sociedades desabaria sem o suporte das traduções. A maneira pela qual a União Européia, umas das grandes construções de sociedade do século XX, constitui-se confirma novamente o papel capital - e em parte camuflado - das traduções na organização das novas sociedades. Formulei regras a respeito da dinâmica das sociedades em um artigo muito breve, e não ousava ir muito longe neste sentido ("Produção, Tradução e Importação"). Atualmente, iria muito além no sentido de uma interpretação sociocultural das traduções, pois é certamente disso que convém falar: a questão das línguas, das literaturas se estabelece frequentemente de maneira específica - dentro (e jamais fora) deste amplo quadro. No artigo em questão, tento mostrar que qualquer sociedade está fundada em atividades centrais (sua "produção", em amplo sentido, não em termos exclusivamente econômicos), que extraem seus princípios seja do testamento cultural que a tradução constitui, seja da interação com sociedades vizinhas (atualmente, a vizinhança cessou de se limitar ao territorial). A dosagem dessas forças depende de muitas coisas, e varia sem cessar; é específica em cada sociedade, por motivos bem compreensíveis. É fascinante observar que o tradicionalismo pode tomar valores negativos, enquanto teria valores positivos para o vizinho. Na realidade, a valorização das forças em questão dá quase sempre lugar a debates, lutas, até mesmo a guerras (civis). Quanto à tradução, ela decorre à primeira vista da importação, mas uma das estratégias seguidas em quase todas as traduções consiste em simular a tradição (o que é conhecido: "ready-made models" na terminologia de Even-Zohar). 
CT: Qual é o papel da tradução em um mundo cada vez mais globalizado?

$J L$ : Permito-me ser breve e lapidar, por motivos de eficiência! E remeto primeiramente a meu artigo sobre a mundialização, publicado há dois anos aproximadamente na impressionante enciclopédia de Gruyter em Berlim (Übersetzung - Translation - Traduction. Berlin: Mouton De Gruyter, 2007). Ali estabeleço o estado da questão, salientando até que ponto os especialistas da tradução ignoraram, até três ou quatro anos atrás, a questão da mundialização. Como os linguistas ou os estudiosos de literatura, evocados na primeira questão, acostumaram-se a considerar as relações de tradução em termos binários, entre duas línguas, uma língua de partida e uma língua de chegada. E é lógico que muitas traduções ocorrem entre duas línguas. É verdade que a maior parte das traduções dão lugar a relações triangulares ou a interações bem mais complexas, no interior de duas ou várias culturas. $\mathrm{O}$ estudo das traduções, a esse propósito, não deixa de ser superficial. - A questão da mundialização, sabemos ou adivinhamos, não é de forma alguma um fenômeno novo. Mas é bastante evidente, por outro lado, que se intensificou e de certa forma se institucionalizou a partir - principalmente - da Segunda Guerra mundial. Em primeiro lugar seria surpreendente que as traduções nem sequer fossem atingidas pela mundialização em questão. Mas neste caso também, a revolução é menos uma questão de princípios do que uma questão de intensidade e de institucionalização.

O fundo do problema é a distribuição paralela de textos/documentos/fragmentos traduzidos em várias línguas, países, redes ao mesmo tempo. Se preferirem, a Bíblia sempre foi difundida segundo tais princípios, mas a coisa podia dificilmente ser espetacular antes da descoberta da impressão (ler Walter Ong: Orality and Literacy, livro entusiasmante). É lógico que a tecnologia ajuda a renovar o jogo da tradução. Mas bem mais que a simples distribuição multidirecional das traduções, é a circulação internacional dos dis- 
cursos - como na internet -, que é frequente e sistematicamente camuflada e ajuda a redefinir a tradução em nosso mundo atual. Inútil dizer que a literatura não está excluída desses universos, - mas é evidente que as revoluções mais espetaculares se situem algures.

CT: Você acha que hoje a tradução é atualmente tão ou mais importante do que foi no passado?

$J L$ : Devo dizer que hesito em responder: não estou seguro que sua hipótese esteja correta. Acabo de insistir no papel das traduções em qualquer sociedade, notadamente durante a fundação das sociedades. Diria antes que as modalidades, as regras, a posição variam segundo muitos parâmetros. Uma coisa ao menos não me causa dúvida: a posição bastante evidente de uma programação internacional/mundial das traduções, consequentemente o caráter deliberado e organizado do conjunto da comunicação traduzida. Mas a tradução tradicional (do tipo binária, mais local) não desapareceu e não desaparecerá.

CT: Como você vê o estado atual e as perspectivas de desenvolvimento dos Estudos da Tradução?

$J L:$ São questões políticas, e não estou certo de ter condições para tratá-las. Seria primeiramente preciso saber se as universidades têm realmente um futuro, e se as ciências humanas vão sobreviver melhor do que parecem poder fazer. A comercialização das universidades (notadamente nas mãos da política nacional dos Estados frente à internacionalização) pode arruinar muitas coisas. É verdade que o papel das organizações internacionais, como a União Européia, não deixou de representar um fator amplamente positivo. $\mathrm{O}$ reconhecimento da tradução até o nível mais elevado, a saber até o nível do doutorado, e isso em múltiplos continentes, é um outro índice. Desejemos assim que a tradução seja salva de ser posta a serviço exclusivamente da economia. Sem os desenvolvimentos em termos de pes- 
quisa que de fato se confirmaram, teríamos dificuldades. Digamos que, globalmente, é notável que nos dias de hoje a questão das traduções ganhe em largura e profundidade, e isso em um momento em que as ciências humanas estão ameaçadas.

CT: Você poderia falar um pouco sobre a questão da linguagem e internacionalização como um aspecto de mudança para as universidades?

$J L:$ Trata-se de questões e de debates que, até onde vai meu conhecimento, ainda não chamaram a atenção nem de nossos dirigentes (políticos ou acadêmicos) nem de nossos pesquisadores, quaisquer que sejam suas origens. A primeira dificuldade, apenas entrevista até os dias atuais, é que a universidade quase nunca refletiu sobre a questão das línguas da universidade, sendo que esta é uma história de vários séculos. O que parece é que as universidades não tiveram realmente problemas de língua. $\mathrm{O}$ mais certo seria dizer que não se aperceberam disso verdadeiramente, nem em suas revoluções sociais, como a de 1968 (exceto na Bélgica, mas o país se lembra com dificuldade da significação profunda do movimento intelectual em questão). As universidades, para se entenderem entre si e em suas relações com as sociedades, contentaram-se em utilizar a língua da Igreja católica, mais tarde a língua de Voltaire, e atualmente - a língua de Shakespeare e George Bush. Se isso causa problemas, e quais, parece que não engaja a universidade. A mundialização tornou-se um fato também para as universidades e isso de maneira espetacular desde o sucesso incrível - e comercializado - do "ranking" (para explicações, basta consultar o Google e os novos instrumentos distribuídos por Google, por exemplo, Wikipedia). Aí também o tema da língua está quase ausente. Ora, em pesquisas muito avançadas, muito recentes, acaba-se de medir o impacto do "monolinguismo" dos rankings, de maneira específica, e da internacionalização das universidades, de modo geral. Torna-se manifesto que as universidades - e os países aos 
quais pertencem - abandonaram aos outros, isto é, aos países anglófonos, a função de nos emprestarem sua língua e, com sua língua, o conjunto da infraestrutura de exploração da pesquisa. Equipes da União Européia calculam atualmente o impacto do domínio do inglês no mundo científico: os números lembram a crise dos bancos. Daí um slogan que lanço a respeito: "Ranking rhymes with Banking". Quero dizer com isso que a falta de senso de responsabilidade entre nossos dirigentes terá - rapidamente - consequências análogas à catástrofe dos mundos bancários, onde uma elite mundial pode arriscar-se às custas do simples membro das sociedades (inclusive às custas do pesquisador, mas também das sociedades bem reais que representam). Todo cidadão se questionará: se há impasse, há como sair dele? É evidente ainda que as infraestruturas são atualmente inexistentes. Nem os linguistas, nem os especialistas da tradução estão verdadeiramente preocupados com a dificuldade. E será preciso tempo - e uma pesquisa difícil e sofisticada - para avançar esquemas de solução. Enquanto isso, não escapamos às lógicas seguintes, conhecidas pelos peritos: $1^{\circ}$ ) as universidades não estão preparadas para a mundialização, exceto talvez em termos de negócios, mas de forma alguma em gerenciamento da comunicação (ou da concorrência!); $2^{\circ}$ ) uma gestão (o management) em matéria de línguas será indispensável, e não poderá ser reduzida a uma (nova) política da língua, como a da União Européia; $3^{\circ}$ ) As línguas científicas na Internet já indicam onde o começo poderia ocorrer; $4^{\circ}$ ) Visto que uma gestão em matéria de língua torna-se necessária, ela é e será relacionada, a fortiori, na mundialização, a uma gestão (um management) da tradução. Questões bem virtuais, imaginárias? O preço que pagarão em breve no mundo inteiro os países e as universidades não será por muito tempo imaginário.

Entrevista concedida a Andréia Guerini e Walter Carlos Costa

UFSC

Tradução do francês de Gilles Abes UFSC

Revisão Claudia Borges de Faveri 